\title{
VIKOR multi-criteria decision making with AHP reliable weighting for article acceptance recommendation
}

Aji Prasetya Wibawa a,1,*, Juwita Annisa Fauzi b,2, Seno Isbiyantoro b,3 ${ }^{\text {b }}$, Rahmat Irsyada b,4, Dhaniyar ${ }^{\mathrm{b}, 5}$, Leonel Hernández c, 6

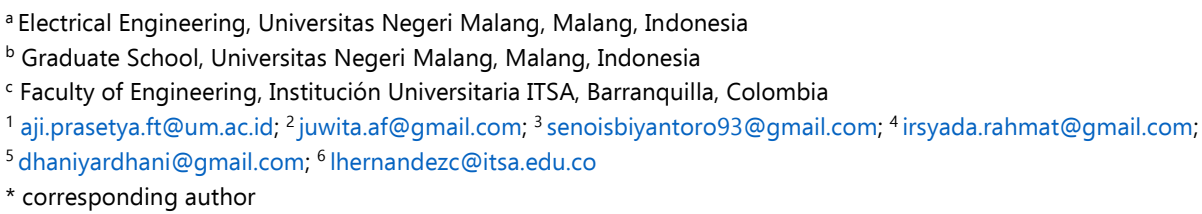

\section{ARTICLE INFO}

\section{Article history}

Received June 28, 2018

Revised March 28, 2019

Accepted March 28, 2019

Available online July 31, 2019

\section{Keywords}

DSS

MCDM

AHP

VIKOR

\section{ABSTRACT}

DSS is built to support the solution recommendation of a problem. AHP and VIKOR are examples of DSS method. Due to VIKOR's subjective weighting, this study combines the AHP and VIKOR approach to create a better and more reliable decision support system. The DSS is used to recommend article acceptance using five criteria: originality, quality, clarity, significance, and relevance. The results showed that AHP-VIKOR outperforms the performance of VIKOR. AHP weighting reliably replaces the subjective VIKOR's initial weighting. The AHP-VIKOR result is more accurate and steadier than VIKOR. Thus, AHP-VIKOR can be presented as a proposed approach for creating a recommendation of scientific article acceptance.

This is an open access article under the CC-BY-SA license.

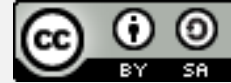

\section{Introduction}

Decision Support System (DSS) enables a more efficient decision-making process [1]. It is built to support a problem solution or an opportunity evaluation. One of DSS variety is Multi-Criteria Decision Making (MCDM). MCDM overcomes severe cases [2] with many criteria or attributes [3]. Furthermore, MCDM can solve real-life problems, especially for a problem with contradictory decision criteria [4]. It works as a selection of the best of several mutually exclusive alternatives, determined by the decisionmaker [5].

MCDM is divided into two approaches: single and hybrid. Single approach uses a particular method such as Analytic Hierarchy Process (AHP) [6]-[9], Data Envelopment Analysis (DEA) [10]-[13], Elimination at Choix Traduisant La Realite (ELECTRE) [14]-[16], Technique for Order of Preference by Similarity to Ideal Solution (TOPSIS) [17]-[19], Analytic Network Process (ANP) [20]-[22], and Vlse Kriterijumska Optimizacija Kompromisno Resenje in Serbia (VIKOR) [23]-[26]. On the other hand, the hybrid approach combines more than one of a single method; for instance, the combination of AHP and VIKOR will be discussed in this study.

AHP method breaks complicated problems of an unstructured situation into variables [27]. Variables are organized into a hierarchical order form, provides numerical values for subjective evaluations of each relative importance of variables. Furthermore, the assessment is synthesized according to the variable with the highest influential priority to the solution [28]. AHP is independently developed on the use of alternative comparison concerning various criteria and estimated weight criteria [3], uses Saaty theory 
[28], [29]. AHP weighting is not only performed to obtain the weight but also to examine weight consistency. This made AHP weighting is valid and reliable. Furthermore, AHP can manage qualitative attributes as a quantitative analysis [30]. Thus, it can be applied in all multi-criteria cases. Instead of its strengths, AHP is very limited in case of development from the predetermined weight of criteria.

In different circumstances, VIKOR aims to derive alternative of the ranking of results as an approximate ideal solution by proposing a compromise solution [31]. This method has advantages in compromising the existing alternatives and can solve discrete decision-making on contradictory and noncommensurable criteria; unit differences between criteria [24]. It will find the closest solution to the overall weight [3]. The disadvantage of the VIKOR method is its subjective initial weighting that is challenging to validate.

The combination of AHP and VIKOR methods is proposed to cover each disadvantage. AHP could improve the validity and reliability of weighting in VIKOR. In other words, the hybrid may produce more consistent weighting criteria. In this paper, AHP and VIKOR will be hybridized for creating a more reliable decision in a manuscript acceptance system.

\section{Method}

This paper uses scientific articles to review as a study case. In general, the publication of scientific articles requires several stages: article submission, review process, and the announcement of review results: whether the article deserves to be published, should be revised or must be rejected [17]. The article publication consumes a relatively long time. The longest stage could be the review process. This study uses a combination of AHP and VIKOR to recommend the review status of an article based on five acceptance criteria as shown in Table 1. Each criterion was marked using C1 to C5 codes according to the priority order of the article evaluation.

Table 1. The DSS criteria

\begin{tabular}{cc}
\hline Criteria Code & Criteria \\
\hline C1 & Originality \\
C2 & Quality \\
C3 & Clarity \\
C 4 & Significance \\
C5 & Relevance \\
\hline
\end{tabular}

This study focused on a review of 18 articles. Five experts assess each article (A1 to A18). Table 2 shows the final decision for each article. This data is valid and used as a baseline of the study. In other words, the best method is an approach with the closest result to the baseline.

Table 2. Expert decision

\begin{tabular}{ccc}
\hline Decision Status & Article Code & Percentage (\%) \\
\hline Accepted & A1,A2, A3,A4,A6,A7,A8, A13, A14,A16, A17, A18 & 66,6 \\
Rejected & A5,A9,A10,A11,A12,A15 & 33,33 \\
\hline
\end{tabular}

Experts assess 18 articles and decide the complete decision for each article. This expert judgement is used for comparison with AHP-VIKOR result. Fig. 1 shows the AHP algorithm. The Pairwise Comparison matrix (in step1) is built using Saaty comparison scale, is presented in Table 3. The algorithm stop condition is based on the value of Consistency Ratio (CR). It must be repeated until CR $\leq 0.1$. 
Algorithm 1: AHP

Step 1: Create a Pairwise Comparison matrix by comparing the degree of importance between criteria using the Saaty comparison scale.

Step 2: Calculate the total of each criterion in one column of the pairwise comparison matrix. The total of each column (TC).

Step 3: Divide each column value by the number of columns to obtain a normalization matrix, $\overline{a_{j k}}=\frac{a_{j k}}{\sum_{i=1}^{n} a_{i k}}$ where $\overline{a_{j k}}$ is the result of pairwise criteria normalization, where $a j k$ is the relative importance scale between two criteria, $\mathrm{n}$ is the number of criteria, and aik represented the relative importance scale in one criterion.

Step 4: Calculate the total each column in the normalization matrix (TCNM) and divide it with the number of criteria to obtain the relative priority of each criterion.

Step 5: Measure the criteria consistency by multiplying each element in the column with its representative criterion relative priority $(\mathrm{RP})$. A consistency matrix $(\mathrm{CM})$ is produced as a result of this process.

Step 6: Calculate the total of each row $(\lambda)$ in CM and divide it by the relevant criterion.

Step 7: Calculate the total of $\lambda$ and divide it with the number of criteria (n) to produce $\lambda_{\max }=$ $\frac{\sum \lambda}{n}$.

Step 8: Calculate the Consistency Index $(\mathrm{CI})$ value, $C I=\frac{\lambda_{\max }-n}{n-1}$.

Step 9: Calculate the Consistency Ratio (CR) value by dividing CI value with random generator value (RI).

Step 10: Check the consistency of criteria weight determination by looking at $\mathrm{CR}$ value. If $\mathrm{CR}>$ 0.1 , then repeat step 5 to step 9 . If $\mathrm{CR} \leq 0.1$, then the process is stopped.

Fig. 1. AHP algorithm

Table 3. Saaty's Comparison Scale

\begin{tabular}{cl}
\hline Intensity of Interest & \multicolumn{1}{c}{ Description } \\
\hline 1 & Both elements are equally important. \\
3 & One element is slightly more important than another element. \\
5 & One element is more important than another element. \\
7 & A powerful element is important than another element. \\
9 & One element is essential than another element. \\
$2,4,6,8$ & Uncertain two adjacent values. \\
\hline
\end{tabular}

Fig. 2 presents the VIKOR algorithm [32] which is used to obtain article ranking. In a matrix $\mathrm{F}$ (Step 2 on Fig. 2), A declared $\mathrm{i}^{\text {th }}$ alternative $\mathrm{i}=1,2,3, n ; C_{\mathrm{xn}}$ declared $\mathrm{j}^{\text {th }}$ criteria $j=1,2,3, \ldots m . x_{\mathrm{ij}}$ is the alternative response $i$ in the criteria $j$.

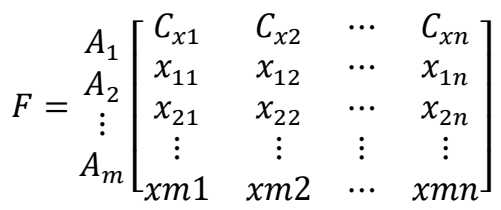

Then the matrix is normalized by the following equation: 


$$
F=\left[f_{i j}\right] m x n
$$

Where $f_{i j}$ is

$$
f_{i j}=\frac{x_{i j}}{\sqrt{\sqrt{\sum_{i=x_{i j}}^{m}}}}, \mathrm{i}=1,2, \ldots
$$

Here, $x_{i j}$ is the value of alternative $A_{\mathrm{i}}$ in $j^{\text {th }}$ criteria.

\section{Algorithm 2: VIKOR}

Step 1: Define the decision-making criteria.

Step 2: Each criterion and alternative is arranged into a matrix $F$.

Step 3: Perform criteria weighting to differentiate the degree of importance among AHP criteria.

Step 4: Determine the positive and negative values as the ideal solution of each criterion and decision of the normalization matrix.

Step 5: Calculate the utility measure of each alternative.

Step 6: Calculate the value of VIKOR index

Step 7: Compromise alternative ranking.

Step 8: Propose the best alternative compromise solution by measuring the minimum VIKOR index.

Fig. 2. VIKOR algorithm

The third step implement the AHP relative priority value as weight. In the step 4, the alternative of the ideal solution of each criterion and decision of the normalization matrix is defined as positive $\boldsymbol{A}_{\boldsymbol{i}}^{*}$ or negative $\boldsymbol{A}_{\boldsymbol{i}}^{-}$. Positive $\boldsymbol{A}_{\boldsymbol{i}}^{*}$ is the highest value of a criterion is the best, $\boldsymbol{A}_{\boldsymbol{i}}^{*}=\max _{\mathbf{j}} \boldsymbol{A}_{\mathrm{ij} \cdot}$. While negative $\boldsymbol{A}_{\boldsymbol{i}}^{-}$ is the smallest value of the criteria is the best, $\boldsymbol{A}_{\boldsymbol{i}}^{-}=\max _{\mathbf{j}} \boldsymbol{A}_{\mathrm{ij}}$. Thus, it could be written as the following equation:

$$
\begin{aligned}
& A^{*}=\left\{\boldsymbol{f}_{i}^{*}, \boldsymbol{f}_{2}^{*}, \ldots, \boldsymbol{f}_{n}^{*}\right\} \\
& A^{-}=\left\{\boldsymbol{f}_{i}^{-}, \boldsymbol{f}_{2}^{-}, \ldots, \boldsymbol{f}_{n}^{-}\right\}
\end{aligned}
$$

Afterward, the decision of the normalization matrix is performed by dividing each $\mathrm{A}^{*}$ and $\mathrm{A}^{-}$ reduction value with initial weight. Then, the actual weight was obtained by multiplying the results of the normalization matrix with the AHP criteria weighting. The utility measure of each alternative (Step 5 on Fig. 2), can be calculated as,

$$
\begin{aligned}
& \mathrm{S}_{i}=\sum_{j=\mathbf{1}}^{n} \boldsymbol{w}_{\boldsymbol{j}} \frac{\left(f_{j}^{*}-f_{i j}\right)}{\left(f_{j}^{*}-f_{j}^{-}\right)} \\
& \mathrm{R}_{i}=\operatorname{Max}_{\mathrm{j}}\left[\boldsymbol{w}_{\boldsymbol{j}} \frac{\left(f_{j}^{*}-f_{i j}\right)}{\left(f_{j}^{*}-f_{j}^{-}\right)}\right]
\end{aligned}
$$

In the sixth step, the VIKOR index could be written as,

$$
Q_{i}=\mathrm{v}\left[\frac{S_{i}-S^{*}}{S^{-}-S^{*}}\right]+(\mathbf{1}-\boldsymbol{v})\left[\frac{R_{i}-R^{*}}{R^{-}-R^{*}}\right]
$$


where $\mathrm{S}^{*}$ is $\operatorname{Min}_{\mathrm{i}}\left(\mathrm{S}_{\mathrm{i}}\right), \mathrm{S}^{-}$for $\operatorname{Max}_{\mathrm{i}}\left(\mathrm{S}_{\mathrm{i}}\right), \mathrm{R}^{*}$ is $\operatorname{Min}_{\mathrm{i}}(\mathrm{R})$, and $\mathrm{R}^{-}$as $\operatorname{Max}_{\mathrm{i}}(\mathrm{R})$; and $v$ was weight ranging from 0 to 1 (generally 0.5 ). The smaller VIKOR index (Qi), then the better the alternative solution. After Qi was calculated (Step 7 on Fig. 2), then there would be three types of ranking: $S_{i}, R_{i}$, and $Q_{i}$. Compromise solutions were seen in $\mathrm{Q}_{i}$ ranking. Finally, the last step measures the minimum VIKOR index based on the following conditions:

1) Acceptable advantage, a difference between the $\mathrm{A}^{(1)}$ and $\mathrm{A}^{(2)}$, the best and the second alternative ranking respectively.

$$
\mathrm{Q}\left(A^{(2)}\right)-\mathrm{Q}\left(A^{(1)}\right) \geq \mathrm{DQ}
$$

Where $\mathrm{DQ}$ is

$$
\mathrm{DQ}=\frac{1}{j-1}
$$

where $\mathrm{J}$ is the number of alternatives.

2) Acceptable stability in decision making. This compromise solution is stable in the decision-making process that could be due to: "vote by majority rule" (when $v>0.5$ ), or "by consensus" ( $v=0.5)$, or "by veto" $(\mathrm{v}<0.5)$.

If any of conditions is not met, then two compromise solutions can be proposed. The first solution selects alternative $\mathrm{A}^{(1)}$ and $\mathrm{A}^{(2)}$, if only Acceptable stability condition in decision making is not met. The second solution chooses alternative $\mathrm{A}^{(1)}, \mathrm{A}^{(2)}, \ldots, \mathrm{A}^{(\mathrm{M})}$, if Acceptable Advantage condition is not met; $\mathrm{A}^{(\mathrm{M})}$ is the alternative determined from the relation.

$$
\mathrm{Q}\left(A^{(M)}\right)-\mathrm{Q}\left(A^{(1)}\right)<\mathrm{DQ}
$$

$\mathrm{M}$ maximum is an alternative, in which the position on adjacent condition.

The calculation of MAX MIN utility measure is S- of $0.89, \mathrm{~S}^{*}$ of $0.04, \mathrm{R}-$ of 0.50 , and $\mathrm{R}^{*}$ of 0.03 . Alternative ranking in this study was an alternative compromise solution or acceptable stability in decision making. The alternative ranking of normal $\mathrm{v}$ value at 0.5 is equal to the calculation when the value of $\mathrm{v}<0.5$ is 0.4 and when the value of $\mathrm{v}>0.5$ was 0.6 . These calculations can be seen in Table 4 .

Table 4. Alternative Ranking

\begin{tabular}{ccccc}
\hline $\begin{array}{c}\text { Article } \\
\text { Code }\end{array}$ & $\mathrm{V}=\mathbf{0 . 4}$ & $\mathrm{V}=\mathbf{0 . 5}$ & $\mathrm{V}=\mathbf{0 . 6}$ & $\begin{array}{c}\text { Alternative } \\
\text { Ranking }\end{array}$ \\
\hline A8 & 0.000 & 0.000 & 0.000 & 1 \\
A6 & 0.084 & 0.082 & 0.081 & 2 \\
A3 & 0.089 & 0.089 & 0.089 & 3 \\
\hline
\end{tabular}

\section{Results and Discussion}

The results of AHP-VIKOR Alternative ranking can be seen in Table 5. The table also consists of general VIKOR ranking and experts' judgments for comparison. VIKOR and AHP-VIKOR ranking mechanisms are the same. Ranking starts from the smallest value of VIKOR index. It is different from expert ranking, where the ranking is based on the article value. Experts recognize the highest value as the first rank. For instance, A1 is the first rank article with a total score of 14. If there are two or more articles have the same value (e.g., A1 and A18), then the order is based on the ascending order of article code. 
Table 5. The result of AHP-VIKOR Alternative ranking

\begin{tabular}{cccccc}
\hline Article Code & Expert & $\begin{array}{c}\text { Article } \\
\text { Code }\end{array}$ & VIKOR & $\begin{array}{c}\text { Article } \\
\text { Code }\end{array}$ & $\begin{array}{c}\text { AHP } \\
\text { VIKOR }\end{array}$ \\
\hline A1 & $1(14)$ & A8 & 1 & A8 & 1 \\
A18 & $1(14)$ & A6 & 2 & A6 & 2 \\
A2 & $2(13)$ & A17 & 3 & A3 & 3 \\
A6 & $2(13)$ & A1 & 4 & A14 & 3 \\
A8 & $2(13)$ & A1 & 5 & A1 & 5 \\
A16 & $2(13)$ & A14 & 5 & A17 & 6 \\
A3 & $3(12)$ & A13 & 7 & A4 & 7 \\
A4 & $3(12)$ & A7 & 8 & A13 & 8 \\
A7 & $3(12)$ & A4 & 9 & A7 & 9 \\
A13 & $3(12)$ & A16 & 10 & A16 & 10 \\
A14 & $3(12)$ & A18 & 11 & A18 & 11 \\
A17 & $3(12)$ & A2 & 12 & A11 & 12 \\
A9 & $4(9)$ & A10 & 13 & A2 & 13 \\
A5 & $5(8)$ & A11 & 14 & A9 & 14 \\
A11 & $5(8)$ & A9 & 15 & A10 & 15 \\
A12 & $5(8)$ & A15 & 16 & A12 & 16 \\
A15 & $5(8)$ & A5 & 17 & A15 & 17 \\
A10 & $6(7)$ & A12 & 18 & A5 & 18 \\
\hline
\end{tabular}

The experts evaluate the articles based on the five criteria: originality, quality, clarity, significance, relevance. It is the same as AHP-VIKOR and VIKOR ranking criteria. In fact, the expert evaluation is conducted subjectively and does not through any weighting mechanisms. Experts only provide three types of decision scales $(1,2$, and 3$)$. The highest value of each criterion is 3 , and the lowest value is 1 . In this case, the article with a score of fewer than ten score is rejected. Here, the rejected articles are A9, A5, A11, A12, A15, and A10. Following the expert judgment in Table 6, the rejected articles rejected by AHP-VIKOR is ranged from 13th to 18th rank: A2, A9, A10, A12, A15, and A5. On the other hand, general VIKOR rejects five articles: A10, A11, A9, A15, A5, and A12.

Table 6. Comparison of Review Recommendation

\begin{tabular}{cccc}
\hline Article Code & Expert & VIKOR & AHP-VIKOR \\
\hline A1 & Accepted & Accepted & Accepted \\
A2 & Accepted & Accepted & Rejected \\
A3 & Accepted & Accepted & Accepted \\
A4 & Accepted & Accepted & Accepted \\
A5 & Rejected & Rejected & Rejected \\
A6 & Accepted & Accepted & Accepted \\
A7 & Accepted & Accepted & Accepted \\
A8 & Accepted & Accepted & Accepted \\
A9 & Rejected & Rejected & Rejected \\
A10 & Rejected & Rejected & Rejected \\
A11 & Rejected & Rejected & Accepted \\
A12 & Rejected & Rejected & Rejected \\
A13 & Accepted & Accepted & Accepted \\
A14 & Accepted & Accepted & Accepted \\
A15 & Rejected & Rejected & Rejected \\
A16 & Accepted & Accepted & Accepted \\
A17 & Accepted & Accepted & Accepted \\
A18 & Accepted & Accepted & Accepted \\
& Accuracy $\%)$ & 100 & 88.9 \\
\hline
\end{tabular}


Table 6 shows a case of comparison between the article's acceptance decision using VIKOR and AHPVIKOR. In this case, the accuracy of VIKOR is higher than AHP-VIKOR. The result shows that the VIKOR result is identical with the expert recommendation. However, it means that the result is subjective since the initial weighting is decided by the reviewers. Thus, those approaches should be compared with different scenarios of initial weighting. While the initial weighting is different, the VIKOR accuracy could also be changed. AHP may reduce weighting subjectivity. Fig. 3 shows the accuracy comparison between VIKOR and AHP-VIKOR.

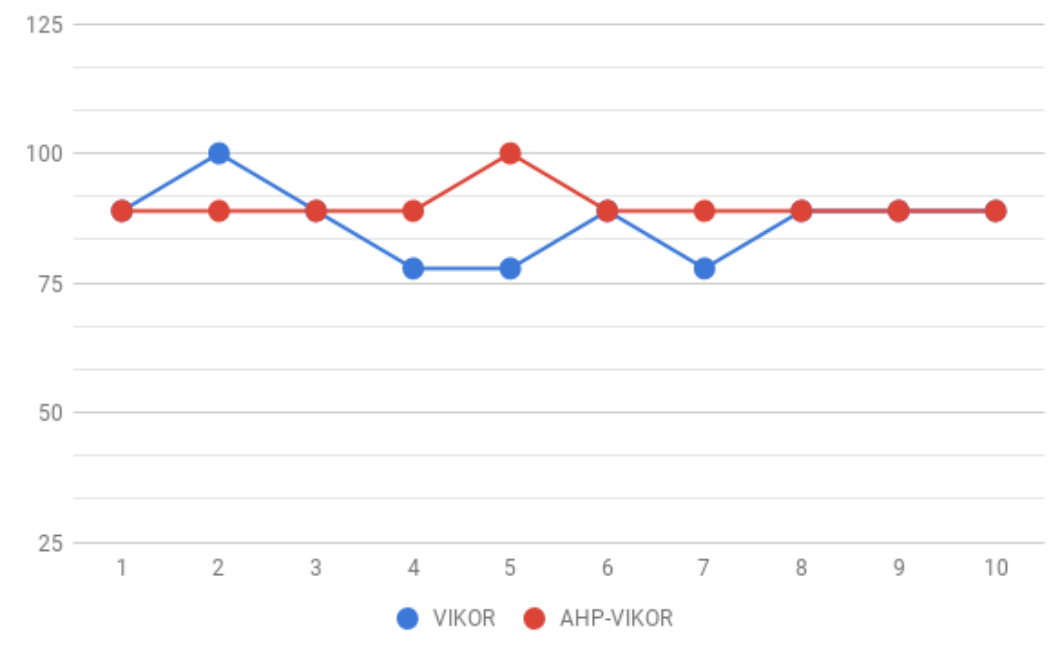

Fig. 3. Accuracy comparison

After tried with ten different scenarios, it seems that the accuracy of AHP-VIKOR is slightly higher than VIKOR. The average accuracy of AHP-VIKOR is $90 \%$, while VIKOR is $87.8 \%$. Moreover, VIKOR's standard deviation (6.3) is higher than AHP-VIKOR (3.5). In short, VIKOR is less stable than AHP-VIKOR. Therefore, AHP-VIKOR outperforms VIKOR in terms of accuracy and stability.

\section{Conclusion}

AHP-VIKOR can be used as a method in decision making in the publication of scientific articles. AHP is used as more reliable weighting criteria for VIKOR decision making. AHP refines the accuracy and stability of VIKOR decision making. Therefore, AHP-VIKOR can be used as an alternative decision making for scientific publications acceptance. To create higher quality research, the variety of criteria, review decision and the article subjects should be enriched. In advance, a combination with a fuzzy-based approach or TOPSIS should be performed for more reliable decision-making result.

\section{References}

[1] National Forum on Education Statistics. "Forum Guide to Metadata: The Meaning Behind Education Data (NFES 2009--805)", US Department of Education. Washington, DC: National Center for Education Statistics., 2009, available at: Google Scholar.

[2] D. Jato-Espino, E. Castillo-Lopez, J. Rodriguez-Hernandez, and J. C. Canteras-Jordana, "A review of application of multi-criteria decision making methods in construction," Autom. Constr., vol. 45, pp. 151162, Sep. 2014, doi: https://doi.org/10.1016/j.autcon.2014.05.013.

[3] M. Velasquez and P. T. Hester, "An analysis of multi-criteria decision making methods," Int. J. Oper. Res., vol. 10, no. 2, pp. 56-66, 2013 available at: Google Scholar.

[4] S. Bhattacharya and V. Raju, "A Condorcet Voting Theory Based AHP Approach for MCDM Problems," Indones. J. Electr. Eng. Comput. Sci., vol. 7, no. 1, p. 276, Jul. 2017, doi: 10.11591/ijeecs.v7.i1.pp276-286.

[5] H. Chiou, G. Tzeng, and D. Cheng, "Evaluating sustainable fishing development strategies using fuzzy MCDM approach," Omega, vol. 33, no. 3, pp. 223-234, Jun. 2005, doi: 10.1016/j.omega.2004.04.011. 
[6] H. Veisi, H. Liaghati, and A. Alipour, "Developing an ethics-based approach to indicators of sustainable agriculture using analytic hierarchy process (AHP),” Ecol. Indic., vol. 60, pp. 644-654, Jan. 2016, doi: 10.1016/j.ecolind.2015.08.012.

[7] S. N. Kamaruzzaman, E. C. W. Lou, P. F. Wong, R. Wood, and A. I. Che-Ani, "Developing weighting system for refurbishment building assessment scheme in Malaysia through analytic hierarchy process (AHP) approach,” Energy Policy, vol. 112, pp. 280-290, Jan. 2018, doi: 10.1016/j.enpol.2017.10.023.

[8] E. Koç and H. A. Burhan, "An application of analytic hierarchy process (AHP) in a real world problem of store location selection,” Adv. Manag. Appl. Econ., vol. 5, no. 1, p. 41, 2015 available at: Google Scholar.

[9] S. Gupta, G. S. Dangayach, A. K. Singh, and P. N. Rao, "Analytic Hierarchy Process (AHP) Model for Evaluating Sustainable Manufacturing Practices in Indian Electrical Panel Industries,” Procedia - Soc. Bebav. Sci., vol. 189, pp. 208-216, May 2015, doi: 10.1016/j.sbspro.2015.03.216.

[10] K. Yu, R. Gong, L. Sun, S. Hu, and Y. Luo, "Empirical Study of Performance Evaluation for the Implementation of Learning Organizations in the Ecology Industry with Data Envelopment Analysis.," Ekoloji Derg., no. 106, 2018 available at: Google Scholar.

[11] T. Y. Lin, "Evaluating the leisure benefits of ecotourism with data envelopment analysis," Appl. Ecol. Environ. Res., vol. 15, no. 2, pp. 33-41, 2017, doi: 10.15666/aeer/1502_033041.

[12] H. Zhou, Y. Yang, Y. Chen, and J. Zhu, "Data envelopment analysis application in sustainability: The origins, development and future directions," Eur. J. Oper. Res., vol. 264, no. 1, pp. 1-16, Jan. 2018, doi: 10.1016/j.ejor.2017.06.023

[13] I. Widiarto and A. Emrouznejad, "Social and financial efficiency of Islamic microfinance institutions: A Data Envelopment Analysis application,” Socioecon. Plann. Sci., vol. 50, pp. 1-17, Jun. 2015, doi: 10.1016/j.seps.2014.12.001.

[14] S. Wan, G. Xu, and J. Dong, "Supplier selection using ANP and ELECTRE II in interval 2-tuple linguistic environment," Inf. Sci. (Ny)., vol. 385-386, pp. 19-38, Apr. 2017, doi: 10.1016/j.ins.2016.12.032.

[15] S. S. Hashemi, S. H. R. Hajiagha, E. K. Zavadskas, and H. A. Mahdiraji, "Multicriteria group decision making with ELECTRE III method based on interval-valued intuitionistic fuzzy information," Appl. Math. Model., vol. 40, no. 2, pp. 1554-1564, Jan. 2016, doi: 10.1016/j.apm.2015.08.011.

[16] J. Peng, J. Wang, and X. Wu, “An extension of the ELECTRE approach with multi-valued neutrosophic information,” Neural Comput. Appl., vol. 28, no. S1, pp. 1011-1022, Dec. 2017, doi: 10.1007/s00521-0162411-8.

[17] C. H. Primasari, R. Wardoyo, and A. K. Sari, "Integrated AHP, Profile Matching, and TOPSIS for selecting type of goats based on environmental and financial criteria," Int. J. Adv. Intell. Informatics, vol. 4, no. 1, pp. 28-39, Mar. 2018, doi: 10.26555/ijain.v4i1.105.

[18] P. Biswas, S. Pramanik, and B. C. Giri, "TOPSIS method for multi-attribute group decision-making under single-valued neutrosophic environment," Neural Comput. Appl., vol. 27, no. 3, pp. 727-737, Apr. 2016, doi: 10.1007/s00521-015-1891-2.

[19] J. Hu, Y. Du, H. Mo, D. Wei, and Y. Deng, "A modified weighted TOPSIS to identify influential nodes in complex networks,” Phys. A Stat. Mech. its Appl., vol. 444, pp. 73-85, Feb. 2016, doi: 10.1016/j.physa.2015.09.028.

[20] P. Chemweno, L. Pintelon, A. Van Horenbeek, and P. Muchiri, "Development of a risk assessment selection methodology for asset maintenance decision making: An analytic network process (ANP) approach,” Int. J. Prod. Econ., vol. 170, pp. 663-676, Dec. 2015, doi: 10.1016/j.ijpe.2015.03.017.

[21] X. Zhang, Y. Deng, F. T. Chan, A. Adamatzky, and S. Mahadevan, "Supplier selection based on evidence theory and analytic network process," Proc. Inst. Mech. Eng. Part B J. Eng. Manuf., vol. 230, no. 3, pp. 562573, Mar. 2016, doi: 10.1177/0954405414551105.

[22] P. Aragonés-Beltrán, M. García-Melón, and J. Montesinos-Valera, "How to assess stakeholders' influence in project management? A proposal based on the Analytic Network Process," Int. J. Proj. Manag., vol. 35, no. 3, pp. 451-462, Apr. 2017, doi: 10.1016/j.ijproman.2017.01.001. 
[23] M. Tavana, R. Kiani Mavi, F. J. Santos-Arteaga, and E. Rasti Doust, “An extended VIKOR method using stochastic data and subjective judgments,” Comput. Ind. Eng., vol. 97, pp. 240-247, Jul. 2016, doi: 10.1016/j.cie.2016.05.013.

[24] S. Opricovic and G.-H. Tzeng, "Extended VIKOR method in comparison with outranking methods," Eur. J. Oper. Res., vol. 178, no. 2, pp. 514-529, Apr. 2007, doi: 10.1016/j.ejor.2006.01.020.

[25] S. Opricovic and G.-H. Tzeng, "A comparative analysis of the DEA-CCR model and the VIKOR method," Yugosl. J. Oper. Res., vol. 18, no. 2, pp. 187-203, 2008, doi: 10.2298/YJOR0802187O.

[26] Y.-H. Huang, G.-W. Wei, and C. Wei, "VIKOR Method for Interval Neutrosophic Multiple Attribute Group Decision-Making,” Information, vol. 8, no. 4, p. 144, Nov. 2017, doi: 10.3390/info8040144.

[27] Z. Turskis and E. K. Zavadskas, "A new fuzzy additive ratio assessment method (ARAS-F). case study: the analysis of fuzzy multiple criteria in order to select the logistic centers location," Transport, vol. 25, no. 4, pp. 423-432, Dec. 2010, doi: 10.3846/transport.2010.52.

[28] T. L. Saaty, "Fundamentals of the Analytic Hierarchy Process,” 2001, pp. 15-35, doi: 10.1007/978-94-0159799-9_2.

[29] T. L. Saaty, "Decision making with the analytic hierarchy process," Int. J. Serv. Sci., vol. 1, no. 1, p. 83, 2008, doi: 10.1504/IJSSCI.2008.017590.

[30] M. Kurttila, M. Pesonen, J. Kangas, and M. Kajanus, "Utilizing the analytic hierarchy process (AHP) in SWOT analysis - a hybrid method and its application to a forest-certification case," For. Policy Econ., vol. 1, no. 1, pp. 41-52, May 2000, doi: 10.1016/S1389-9341(99)00004-0.

[31] S. Opricovic and G.-H. Tzeng, "Compromise solution by MCDM methods: A comparative analysis of VIKOR and TOPSIS,” Eur. J. Oper. Res., vol. 156, no. 2, pp. 445-455, Jul. 2004, doi: 10.1016/S03772217(03)00020-1.

[32] J. R. San Cristóbal, "Multi-criteria decision-making in the selection of a renewable energy project in spain: The Vikor method," Renew. Energy, vol. 36, no. 2, pp. 498-502, Feb. 2011, doi: 10.1016/j.renene.2010.07.031. 